\title{
IT'S ABOUT BLOODY TIME AND SPACE
}

\section{LOLITA BUCKNER INNISS*}

\begin{abstract}
Time frames relationships of power, especially in the context of law. One of the clearest ways in which time is implicated in both law and society is via discourses about women's biological functions. This Article is an introduction to a larger project that analyzes legal discourses regarding a crucial aspect of women's calendrically-associated biological functions: women's menstrual periods. Over the course of the project, I explore legal discourses about menstruation through the notion of what literary theorist Mikhail Bakhtin calls "chronotopes"- a connectedness of temporal and spatial relationships. Temporality, Bakhtin argues, is closely associated with certain paradigmatic spaces, and the combination of shapes, ideologies, and identities. Legal discussions of women's menstrual bleeding are key sites for the discursive creation and maintenance of certain ideologies of womanhood. These discussions appear in a wide variety of contexts and in ways that either explicitly reference or implicitly index ideologies of female identity. All are characterized by efforts to mark them as narratives linked to other temporally prior or future moments, and are often indices of chronologically or spatially related stigmas and taboos. While legal discourses of menstruation do not give a complete account of the category "woman," they provide cogent examples of how womanhood ideologies are constructed in legal contexts.
\end{abstract}

\section{INTRODUCTION}

One of the clearest ways in which time is implicated in both law and society is via discourses about women's biological functions. Especially crucial to women's roles in biological timekeeping is the process of menstruation. Because of its roughly monthly occurrence over multiple decades of a woman's life, menstruation is - to borrow a word from technology - a self-clocking process, one that is legible as a time-teller without the need for a separate clock signal or other source of synchronization. ${ }^{1}$ Women across cultures have long talked about their menstrual cycles as "my time of the month," an

\footnotetext{
* Dean and Provosts' Professor of Law, University of Colorado Law School, Ph.D., LLM with Distinction, Osgoode Hall Law School, York University. J.D., University of California, Los Angeles; A.B., Princeton University.

${ }^{1}$ Oliver C. Ibe, Fundamentals of Data Communication Networks 26 (2017).
} 
expression that captures rather succinctly the personal and temporal nature of menstruation.

Despite the self-regulatory nature of women's menstrual periods, for centuries, girls and women have frequently been required to diary the beginnings and ends of their menstrual cycles, as if they could not take place without such external regulation. ${ }^{2}$ This calendarization of menstruation is largely a method of feminine surveillance, one that ensures that girls and women can themselves control, or have others control, their abilities to reproduce. ${ }^{3}$ Menarche, or the first onset of menstruation, is the start of the clock, for it is often seen as a sign of socially becoming a woman, of fertility, and of sexual availability. This is true notwithstanding the fact that being in the midst of menstruating is often deemed sexually unappealing and socially abhorrent.

Menstruation as a time-teller is perhaps not so unusual given that the human condition mandates that we are all up against the clock, moving towards the ultimate end: death. It is often said, however, that time governs women's lives differently than it does for men. This is captured in the centuries-old aphorism: "A man may work from sun to sun, but a woman's work is never done." This saying is frequently addressed, directly or indirectly, in literature on the concept of social reproduction - engagement in the activities required to maintain and recreate life, both on a daily basis and over generations. ${ }^{4}$ Social reproduction is often gendered, as women undertake much of the labor needed to ensure its occurrence. ${ }^{5}$ The notion of women's unending work relates to the notion of both time and space. The man envisioned in this folk saying leaves home, a space of respite, journeys into the world of toil, and at the end of the day returns to claim

\footnotetext{
${ }^{2}$ Lolita Buckner Inniss, (Un)common Law and the Female Body, 61 B.C. L. ReV. ELEC. SuPPLEMENT I.-95, I.100 (2020) (citing Margaret H. Sanger, Family Limitation, in 1 Documenting First Wave Feminisms: TRANSNATIONAL COLlaborations AND CROSSCURRENTS 280, 282 (Nancy Margaret Forestell \& Maureen Anne Moynagh eds., 2012)).

${ }^{3} I d$.

${ }^{4}$ Shirley Lin, “And Ain't I a Woman?”: Feminism, Immigrant Caregivers, and New Frontiers for Equality, 39 HARV. J.L. \& GENDER 67, 77 (2016). For a more detailed discussion of social reproduction theory and gender, see HeIdi GotTFRIED, GENDER, Work, AND ECONOMY: UnPACKING THE GLOBAL ECONOMY (2013); Kate Bezanson, Gender, the State, and Social Reproduction: Household InSECurity in Neo-Liberal TIMES (2006).

${ }^{5}$ See Mary Romero, Beyond Belonging: Challenging the Boundaries of Nationality: Nanny Diaries and Other Stories: Imagining Immigrant Women's Labor in the Social Reproduction of American Families, 52 DePAul L. Rev. 809 (2003) (asserting that immigrant women are often used to reproduce the upper-middleand upper-class American, as well as worldwide, family lifestyles).
} 
his well-earned rest. In contrast, the ideal woman of this saying is ever ensconced within the home. At home, the ideal woman works without ceasing, often laboring under the belief that she (and all that she stands for) would cease without her work. This hypothetical woman is an artifact of the cultural structuring of gendered labor roles, but she is not only from days of yore. The COVID-19 crisis has brought heightened attention to how even contemporary women who work full time jobs outside the home have faced immense pressure to perform their work inside the home along with those outside jobs. During this crisis, some women's outside jobs have, without much notice, migrated into the home with them, complicating and enlarging the already endless list of household duties that many women shoulder. Notwithstanding contemporary ideas about the usefulness of gender, or gender binaries, it remains the case that time is a device of its very own for women, or women-identifying people. There is a "women's time," and it is "cyclical, natural, task-oriented, relational, and embedded."

Women are thus both temporal and atemporal agents, acting as biological timekeepers via the presence and absence of the biological imperative of menstruation, and yet acting outside of standard formulations of time because of certain social and cultural norms. Perhaps unsurprisingly, the extent to which women characterize their own social, legal, and political progress is itself often related to time and space. This may be an effort to harness the power of chronological assessments, and ultimately of historical judgments, in ways that have often eluded women as a class. To have one's actions fixed in time is to have one's spatial presence acknowledged. This is seen in how eras of feminism have been described in chronological "waves." Whether and how these waves have operated and served women is part of a question-begging generation gap in feminism. One aspect of the larger feminist program, assuming for a moment that there is any one single program, is thus for women to lay claim to time and to their own space within time. But in order for women to do that, there must be a broader acknowledgement of the workings of legal and social time-space dynamics in relation to women's bodies.

\footnotetext{
${ }^{6}$ Valerie Bryson, Gender And the Politics of Time: Feminist Theory And Contemporary Debates 122 (2007)

${ }^{7}$ While the phrase "first wave" has been commonly used and understood for decades, it is important to note that the idea of a first wave was not deployed until the 1970s, when it was used in counterpose to the second wave of the feminist movement. First wave is thus a post hoc description of the first wave by women who did not themselves experience the first wave. See, e.g., Marlene LeGates, In Their Time: A History of FEMINISM IN WESTERn SOCIETy (2001).
} 
Women's menstrual bleeding is a key site for querying time, space, and the time-space continuum, which has particular importance in legal contexts. ${ }^{8}$

This Article is an introduction to a larger project that analyzes legal discourses regarding crucial aspects of women's calendrically-associated biological functions: the start, conduct, and end of women's menstrual periods. The project explores legal discourses about menstruation through the notion of what literary theorist Mikhail Bakhtin calls "chronotopes"- a connectedness of temporal and spatial relationships. ${ }^{9}$ Temporality, Bakhtin argues, is associated with certain paradigmatic spaces. The central claim of this Article is that discussions of women's menstrual bleeding in legal contexts are important aspects of the discursive creation and maintenance of certain time- and space-related ideologies of womanhood. After this introduction, the Article proceeds by briefly addressing the meaning and nature of discussions of blood in socio-legal discourse and especially of menstruation is such contexts. Next, the Article offers a personal narrative that helps to explore one common focus on menstruation seen in legal cases: discourses about child sexual abuse. The Article then explains the use of chronotopes in the context of legal discourse. It concludes by suggesting that while legal discourses of menstruation do not give a complete account of the category "woman," they provide cogent examples of how womanhood ideologies are constructed in socio-legal contexts.

\section{Law Talk About Blood}

Discussions of blood are ever-present in legal discussions. Blood in the context of law is frequently about life and death, which are both ultimately other aspects of the relationship between blood and time. Legal discourse about blood also frequently evokes civic belonging and relatedness, signaling attachments to members of a particular polity and thus to geopolitical spaces. Consider the Latin expression jus sanguinis, which translates as "right of blood." This refers to the possession of legal or political rights

\footnotetext{
${ }^{8}$ Besides menstruation and its absence, another site for chronotopic analysis of legal discourses involving women's biological functions involves pregnancy. Inniss, supra note 2, at I.-100 ("[B]ars on abortion are rendered more illegible because the premise for these bars has traditionally rested upon a temporally-based assessment that measures the development of the pregnancy by stages and then applies names such as blastocyst, zygote, embryo or fetus, going from the stage immediately after conception and moving up to the stage closest to birth.").

${ }^{9}$ M. M. Bakhtin, The Dialogic Imagination 84-85 (Michael Holquist ed., Caryl Emerson \& Michael Holquist trans., 1981).
} 
within a nation state that comes from biological descent via one or both parents. ${ }^{10}$ Blood has also played a role in religious, racial, and ultimately legal definitions of belonging in the context of the European settlement of the Americas. ${ }^{11}$ Blood often stands for the nation itself and for national sacrifices in times of war. ${ }^{12}$ In the latter context, blood frequently signals victimhood and heroism. Blood, in all of these contexts, is a metonymy of some larger idea or ideology. ${ }^{13}$ Blood as a metonymy captures the legal, political, and social norms and processes that shape geographic boundaries and belonging within such bounds. ${ }^{14}$ What is often unstated in these rhetorical outings, however, is that what we typically mean is men's blood. ${ }^{15}$

\footnotetext{
${ }^{10}$ Myres S. McDougal, Harold D. Lasswell \& Lung-Chu Chen, Human Rights and World Public Order: The Basic Policies of An International Law of Human Dignity 879 (2018). Jus sanguinis citizenship is contrasted to jus soli, citizenship by place of birth. Most jurisdictions use some combination of the two systems in determining citizenship rights. Id.
}

11 "Limpieza de sangre," literally "cleanliness of blood" was a concept developed in fifteenth-century Spain that referred to a person without Jewish, Muslim, or heretical ancestry. This became a concern in Spain and in some other nations when persecuted Jews and Muslims began converting to Christianity in significant numbers. These conversos, or converts, were dubbed New Christians, and those claiming to have limpieza de sangre were designated Old Christians. Often only those with limpieza de sangre could emigrate to the Americas, obtain inheritance rights or gain other opportunities. Once some European settlers reached the Americas, limpieza de sangre also came to include European racial "purity" exclusive of indigenous or African mixture. Maria Elena Martinez, Genealogical Fictions: Limpieza de SANGRe, Religion, and GeNDER IN COLONIAL MeXICo 270-73 (2008).

${ }^{12}$ Sarah J. Purcell, Sealed with Blood: War, Sacrifice, and Memory in Revolutionary America (2002). The author writes in reference to the Revolutionary War: "Public memory meant that the "wounds, that stream'd with blood' no longer belonged only to the men who fought but to the whole American people. Through the process of commemoration, mere public memory of the war was transformed into the 'Bloodbought fame' that would become the new nation's reputation." Id. at 20.

${ }^{13}$ Jules Zanger, Metaphor into Metonymy: The Vampire Next Door, in Blood ReAD: The VAMPIRE AS METAPHOR IN CONTEMPORARY CUltURE 17, 20 (Joan Gordon \& Veronica Hollinger eds., 1997). Metonymy is a rhetorical device that pairs or replaces words from the same semantic field in order to communicate ideas.

${ }^{14}$ Nicola Pratt, Embodying Geopolitics: Generations of Women's Activism in Egypt, JoRdan, AND LEBANON 5-6 (2020).

${ }^{15}$ For example, in the Spanish notion of limpieza de sangre, or cleanliness of blood as a construct connoting religious and racial purity and ultimately eligibility to civic membership, blood purity was typically assessed via male lineage. MARTINEZ, supra note 11, at 49-50. Jus sanguinis was also historically based on male ancestry in many legal systems, including the United States. Kristin A. Collins, Illegitimate Borders: Jus Sanguinis Citizenship and the Legal Construction of Family, Race, and Nation, 123 YALE L.J. 2134, 2134-36 (2014). 
Discussions of women's blood has often had a much narrower valence, both literally and figuratively, and it is often centered on specific concerns, ${ }^{16}$ such as those seen in the present project on women's menstrual blood. Menstrual blood discussions, like broader discussions of blood, may also represent rhetorical undertakings where one thing relates to or takes the place of another in discourse ${ }^{17}$ However, figurative discussions of women's blood offer a reminder that although metonymy can be used to highlight or center concepts and ideas, it also may be used to obscure, subordinate, or suppress wider meanings. ${ }^{18}$

In order to assess how menstruation discourses appear in legal discussions, I looked at one narrow example of "law talk": published legal opinions that discuss menstruation. ${ }^{19}$ I designed Boolean search strings that would yield a group of cases that was sufficiently representative in number and yet recent enough to reflect contemporary ideas about menstruation. I thus used the following Boolean search string in Westlaw:

$$
\text { menstruat! \& DA(aft 12-31-2018 \& bef 01-01-2020). }
$$

This search yields seventy-one results, excluding secondary discussions of the issue. The cases covered a wide variety of contexts, with many centering on medical malpractice, health, and - most frequently present—sexual assault. One immediately striking feature is that several of the cases are unpublished opinions. Modern courts sometimes forego

\footnotetext{
${ }^{16}$ Consider, for example, that for decades across several U.S. jurisdictions there were laws that compelled premarital and/or prenatal blood testing of women, ostensibly to prevent the passage of syphilis to offspring. See Allan M. Brandt, No Magic Bullet: A Social History of Venereal Disease in the United States SINCE 1880, at 150 (1985). Premarital and/or prenatal blood tests for women were, however, not only aimed at protecting infants who might contract the disease. Such blood tests were also crucial to protecting the sanctity of womanhood and motherhood, since an "innocent" woman, one who had no pre-marital or adulterous sexual relations, could not have venereal disease unless she came into contact with a "sinful" man after entering into a marriage. $I d$. at 35 .

${ }^{17}$ See generally Dana Medoro, The Bleeding of America: Menstruation as Symbolic Economy in PYNCHON, FAULKNER, AND MORRISON (2002) (asserting that there is a pervasive presence of menstrual blood in some of the U.S. literary canon and that this "bloodiness" is symbolic of how the early American colonies, and later the new states, were infused with feminine norms that offered both the possibilities of a "curse" and a "cure" for the political ailments of settlers).

${ }^{18}$ Zanger, supra note 13 , at 17.

19 "Law talk," or discourses about law, can occur in any number of contexts, including written and spoken communications, and in formal and informal settings. It may, moreover, occur in communications by legal and non-legal actors. See, e.g., Susan L. DeJarnatt, Law Talk: Speaking, Writing, and Entering the Discourse of Law, 40 DuQ. L. Rev. 489 (2002).
} 
formalized, representative decisions, choosing to leave some cases "unpublished," that is, some decisions are intentionally framed as not constituting a part of legal precedent. This may be for many reasons, such as the volume of similar cases, the absence of legal merit in some cases, and/or the need to ensure quality by limiting the number of published opinions written. ${ }^{20}$ It is worth querying, however, the relationship of the topic heremenstruation - to courts' cross-jurisdiction decisions not to publish many of the cases.

Additionally, a number of the case narratives seen in the search results are characterized by efforts to link menstruation to temporally prior or future moments, often in the form of reports of prior, present, and future health or illness, and assertions about prior chastity, or current and subsequent unchasteness. ${ }^{21}$ Several noteworthy cases discuss menstruation as an almost protective talisman that sexual assault victims were able to wield as a shield against initial or continuing sexual assault. ${ }^{22}$ Some cases were clear in their articulation of time-place aspects of menstruation, such as where menstruating girls or women were treated as pariahs and either exiled directly by fiat or less directly by voluntarily withdrawing themselves from physical or social activities

\footnotetext{
${ }^{20}$ Boyce F. Martin Jr., In Defense of Unpublished Opinions, 60 Oніо Sт. L.J. 177, 181-83 (1999). While some jurists have complained that the creation of unpublished decisions is a valid response to ballooning numbers of cases wherein issues are repeated, others have expressed the concern that unpublished decisions are sometimes of lower quality, and that not publishing decisions creates problems of "predictability, accountability, responsibility, and reviewability." William L. Reynolds \& William M. Richman, Elitism, Expediency, and the New Certiorari: Requiem for the Learned Hand Tradition, 81 CORNELL L. Rev. 273, 284 (1996).

${ }^{21}$ See, e.g., Slats v. State, No. A-12313, 2019 WL 4302861, at*1-2 (Alaska Ct. App. Sept. 11, 2019) (“In this appeal ... [Slats] argues that since L.W. was menstruating at the time of the alleged assault, evidence that she previously engaged in anal sex with her boyfriend while menstruating would tend to show that she consented to anal sex with Slats.").

${ }^{22}$ See, e.g., People v. Ramos, No. A156046, 2019 WL 2521274, at*1 (Cal. Ct. App. June 19, 2019) (including the prosecution's evidence that the defendant had vaginal intercourse with the child victim until she began menstruating, whereupon the defendant ceased in order to prevent impregnating the child and began other kinds of sexual abuse); see also Alonge v. Chappius, 12-CV-542 (KAM), slip op. at 2 (E.D.N.Y. Apr. 16, 2019) ("[The assailant] told [the victim] that he wanted to see whether she had lied about menstruating .... After [the victim] removed her clothing, the assailant told her to turn around .... [The victim] then observed the man return down the stairs and enter the elevator."); State v. DeJesus, 194 Conn. App. 304, 306-07 (2019) ("When the victim was ten years old, she began menstruating, prompting the defendant to stop the sexual abuse."); Washington v. State, No. 01-17-00905-CR, 2019 WL 1064581, at *2 (Tex. App. Mar. 7, 2019) ("Appellant continued to have sexual intercourse with [the child victim] twice a week until she began menstruating.").
} 
during the time of menstruation. ${ }^{23}$ Yet other cases query whether women's blood in underpants is non-menstrual or menstrual, and, correspondingly, evidence of an alleged child rapist's guilt or innocence. ${ }^{24}$

Cases involving child sexual assault are particularly salient for chronotopic analysis. Childhood is chronotopic in the utmost, for childhood is a time and a space apart from the condition in which most standard human lives are spent: as adults. Childhood is, of course, about chronological time, since it describes the temporal period before adulthood begins. Childhood is also, however, inherently spatial, since the boundaries between childhood and adulthood are akin to domains that vary across culture and within legal, social, cultural, and other settings. The latter category of cases involved the assessment of whether blood was menstrual or not; thus, the blood signaled not the usual frontier between childhood and womanhood but between victim and non-victim status. This category of cases has a particular resonance for me, as it relates to the first instance in which I heard discussions of menstruation.

\section{My Story About Women's Blood and the Law}

When I was six years old, my mother sent me to live with my aunt and her ten children while my mother tried to recover from a bitter divorce and the difficulties that ensued. I lived with my aunt for almost two years. When I arrived there, I was a babyish (though not a baby) girl, and I had little exposure to or understanding of the ways of men and women. When I left my aunt's house to return to my mother, my understanding had greatly expanded, thanks to the doings of my cousins. My aunt bore her first child at age fourteen, and that child, her eldest, was seventeen when I was six. He was called Junior, and he was a friendly, good-natured, chubby boy. Junior cared for all the younger children and for the household besides. He was my aunt's trusted lieutenant, and it was to Junior that we went with all our problems. Junior was mother, father, and doting sibling all rolled into one, for he offered both loving assurance and stern guidance, and he cheerfully turned a blind eye to our minor misbehavior. But as reliable he was within the house, Junior — once outside the house — had a penchant for trouble, much of which was not of his own making.

\footnotetext{
${ }^{23}$ See People v. Linderman, 2019 IL App (1st) 180472-U, $₫ 40$ (Ill. App. Ct. Sept. 3, 2019) (noting that when minor victim left her father's house to avoid sexual contact, the father assumed that she left his home because she was menstruating).

${ }^{24}$ See, e.g., Whitley v. Farris, 793 F. App'x 680 (2019) (noting that the victim's mother testified that she regularly checked the victim's underpants and never saw any blood); see also Mashburn v. State, 124 N.E.3d 637, 2019 WL 1475096, at*1 (Ind. Ct. App. Apr. 4, 2019) (citing evidence that the victim's mother found blood in the victim's underwear before she had begun menstruating).
} 
There was very little money available at my aunt's house, so the older children got by however they could. For some of the more rascally of my aunt's children, this often meant five-finger discounts taken at local stores. For the good kids like Junior, survival usually meant odd jobs around the neighborhood. One of Junior's jobs involved doing heavy housecleaning for a family in the neighborhood. Junior often regaled us with stories about all the wonders of their home - appliances and plentiful food figured prominently in these accounts. Adding to the wonder was the fact that Junior's employers were white, as were most of my aunt's neighbors in the then semi-rural eastern Los Angeles county town. I know now that the people for whom Junior worked were not rich; none of the neighbors were, but they were much better off than we were in a household of numerous children headed by my aunt and her sixth husband.

One day, a few hours after Junior had arrived home from working, the police came to talk to my aunt. The police were no strangers at my aunt's house, as some of the older children had seen their share of run-ins with the law. So, I didn't think much of the visit. But this time the police visit involved something serious - something to do with a thirteen-year-old who lived at the house where Junior worked, and blood, and panties. It seems that the girl's mother had found a pair of the girl's bloodied underpants hidden somewhere. When the mother, furious, confronted the girl about the bloodied underpants and how they had gotten that way (since, to the mother's knowledge, the girl didn't have her period yet), the girl told her mother that Junior had knocked her down on the kitchen floor he was mopping and raped her, causing her to bleed. My aunt was livid, and she told the policeman that the girl had lied, as Junior would never have done such a thing. The girl, my aunt argued, was probably having her period and had hidden the dirty underwear instead of washing them as she should. The police left without arresting Junior, but their visit cast a heavy pall.

We children passed a sleepless night — a night made all the more frightening after one of my cousins said that the white people (not just the girl's family, but some nameless, faceless, collectivized mob) might come and kill Junior because of what happened. Junior was allowed to remain free pending months of hearings and trips downtown to see important people in the courthouse and at the police station. Finally, the matter somehow went away. I was never clear on how it was resolved, for no one would talk about it. If the claims of rape of a young, white girl alone weren't enough to take the story out of familial discourse, the part about panties — and bloody panties at that - had the effect of placing the story under almost judicial gag order. Junior stopped working as a housecleaner for white people after that. I was left to wonder and piece it together. 
When I experienced this situation as a six-year-old, I was baffled. What was rape? What was a period, besides the thing that came at the end of a sentence? Whatever these things were, they both seemed to involve danger. But I was most fixated on the part of the story about the girl bleeding in her underpants. It seemed terrifying, wrapped up as it was with gender, allegations of sexualized violence, class, and race. As I grew older, the story became emblematic of the silence, fear, and mystery surrounding women's menstruation. And the presence of such discussions in legal settings further added to the complexity and confusion. Junior's legal case, and the story of a thirteen-year-old girl's bloody underpants, lingered in my mind for years, and it has, in many ways, profoundly shaped ideas of time and place, violence, subjectivity, race, sex, and gender. The story was, I have come to understand, ideal for chronotopic analysis within a legal context.

\section{The Chronotope and Its Role in Understanding Legal Stories}

Bahktin's chronotope was borrowed from early-twentieth-century relativity theory. ${ }^{25}$ The chronotope is "a unit of analysis for studying language according to the ratio and characteristics of the temporal and spatial categories represented in that language. ${ }^{26} \mathrm{In}$ its simplest meaning, the idea of the chronotope seeks to explain the fundamental relationship between time and space in literary contexts, and their functions in specific literary genres. Chronotopic analysis of literature involves a process wherein the readeranalyst looks at the actions of time and their descriptions in space. This may involve actions occurring within specific, historically instantiated time periods. However, in its most typical framing, the chronotope does not necessarily imply a historical interpretation. Chronotopes are mechanisms wherein time and space are deeply related, often interdependent, but not in lock step. Use of chronotopes demonstrates how all events benefit from being viewed in a time-space prism. For this reason the concept of the chronotope also provides a particularly useful perspective for querying legal discourses. ${ }^{27}$ They are especially useful in assessing discourses that address women in biopowered time-space frames. ${ }^{28}$

\footnotetext{
${ }^{25}$ BAKHTIN, supra note 9 , at 84 .

${ }^{26} I d$. at 425 .
}

${ }^{27}$ Scholar Mariana Valverde has, for example, used the chronotope as a framework for analyzing the spatiotemporal workings of law and other forms of governance. See Mariana VALVERDE, Chronotopes of Law: JURISDICTION, SCALE AND GOVERNANCE (2015).

${ }^{28}$ Biopower is a concept created by Michel Foucault. It concerns the ways in which contemporary nation states wield their regulatory regimes in order to achieve "the subjugations of bodies and the control of populations.” Michel Foucault, The History of Sexuality Vol. 1: The Will to Knowledge 140 (1998). 
What does chronotopic analysis yield for legal discourses, whether they occur in legal decisions or in my story? Performing a chronotopic analysis requires first identifying the time-space aspects of a legal story and, next, determining their meaning. My story requires the reader-analyst to recognize that it is told from the perspective of a young child, and that the story focuses on two other children. Hence, it occurs well within the time-space arena of childhood. Next, it implicates race, which itself is rich in chronotopic import. Social divisions between Black and white people, divisions at one time explicitly created by formal law, are creatures of both time and space. ${ }^{29}$ In addition, the story involves distinctions in class and, relatedly, a reverse of gendered work expectations - my cousin Junior, a large, teenage, Black boy, performed housework for a white family, laboring in the house instead of in the more masculine space of the outdoors.

Moreover, the alleged assault was said to occur at the heart of the white home-in the kitchen. The kitchen is itself a womanly space within a womanly space. ${ }^{30}$ The kitchen has also long had racial connotations, given the history of Black women's employment in the kitchens of white homes in the United States. ${ }^{31}$ Before and for the decades immediately after the general emancipation of enslaved Black people in the United States, cooking for white families was one of the primary jobs that Black women performed. This was so much the case that by the end of the nineteenth century there was even a popular, mainstream craze for "mammy" cooking that appropriated the voices and recipes of Black women domestics. ${ }^{32}$

\footnotetext{
${ }^{29}$ VALVERDE, supra note 27, at 45-48 (discussing both the spatial and temporal aspects of racial difference and boundary-setting measures like segregation, and the role of spatiotemporal movement in redefining racial identities). Slave plantations have been described as racial chronotopes because of the temporality of seasonal agricultural and the racially-related distributions of power within the space. YOLANDA MARTíNEZ-SAN Miguel, Contemporary ArChipelagic Thinking: Towards New Comparative Methodologies and DISCIPLINARY FORMATIONS 115 (2015).

${ }^{30}$ See Margaret Park Johnson, Gender Dichotomies in the Kitchen: Feminine and Masculine Qualities of Spaces and Artifact (2012) (M.S. thesis, University of North Carolina at Greensboro), http://libres.uncg.edu/ir/uncg/f/Johnson_uncg_0154M_10947.pdf [https://perma.cc/4UYN-8A5W] (noting that the kitchen has traditionally been a space under the domain of women). "Housework is spatiotemporally configured to uphold an idealised image of family life." Ellen Gordon-Bouvier, Crossing the Boundaries of the Home: A Chronotopical Analysis of the Legal Status of Women's Domestic Work, 15 InT'L. J.L. CONTEXT $479,479,485$ (2019) (asserting that domestic work is spatially and temporally hidden in the home, with corresponding invisibility in the law).

${ }^{31}$ See, e.g., Rebecca Sharpless, CoOKIng In Other Women's Kitchens (2010).

${ }^{32} I d$. at xxiv-xxv. As one author observes, the figure of the "mammy cook" is embedded in the white Southern psyche, as well as the national consciousness as a whole. DORIS WitT, Black HunGER: SOUL FoOd
} 
Next, chronotopic analysis of my story is characterized by a tension between two distinct, although connected, temporalities: the history of the alleged crime and that of the investigation through which the history of the crime is progressively reconstructed. These stories are carried by a first-person narration. But most central to the story, and what makes its recounting highly relevant here, is that it involves a discussion of menstrual blood in a legal context. Menstruation, as discussed earlier, is a key site for chronotopic analysis, existing as it does to create time-space boundaries in how we understand womanhood. The role of that blood in determining guilt and innocence is also crucial to a chronotopic analysis, for guilt and innocence may themselves be thought of as determinations along a time-space continuum. ${ }^{33}$

\section{CONCLUSION}

It has long been understood that gender is culturally produced, and that production is largely accomplished via discourse. ${ }^{34}$ This does not mean that no other mechanisms act to inscribe gender or that there are no material bases for the creation of gendered subjects. Rather, discourse creates and maintains social norms that materialize bodies and sex. The term "woman" is often underexplained because it fails to fully account for intersectional modalities such as race, class, or ethnicity. ${ }^{35}$ But another area where discourse of womanhood often falls short is in articulating the importance of both time and place in women's lives and how those factors contribute to defining womanhood. Here is where the chronotope has some of its greatest purchase. Chronotopic analyses call for a consideration of how time and space work in tandem to create meaning. The notion of the chronotope makes it possible to grasp various aspects of the role of time and space that resist a fine analysis of descriptive passages assessing the meaning or the characteristics of time space. By combining time and space, the chronotope takes into account both the peculiarities of the narrative (because space unfolds there in time) and the characteristics of time, which dynamically affect the dimensions of space.

And America 61 (2004). See generally Toni Tipton-Martin, The Jemima Code: Two Centuries of AFRICAN AMERICAN COOKBOOKS (2015) (discussing research on African American-authored cookbooks and how those have contributed to America's food culture for centuries).

${ }^{33}$ Guilt and innocence are often framed as "before" and "after" binary spaces that can somehow be made visible after presentations of evidence in legal settings. However, guilt and innocence are better described as the outer boundaries of "a whole region of cases whose outcome is determined based on "deterministic excuses." 'Lolita Buckner Inniss, "Other Spaces” in Legal Pedagogy, 28 HaRV. J. Racial \& Ethnic Just. 67, 69 (2012).

\footnotetext{
34 Judith Butler, Gender Trouble: Feminism And the Subversion of Identity 10 (1990).

${ }^{35} \mathrm{Id}$. at 3.
} 